\title{
Transmutation Fuel Performance Code Conceptual Design
}

Gregory K. Miller

Pavel G. Medvedev

March 2007

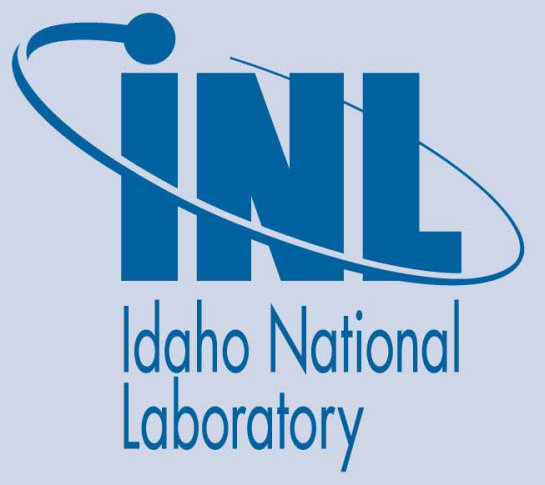

The INL is a U.S. Department of Energy National Laboratory operated by Battelle Energy Alliance 
INL/EXT-07-12306

\section{Transmutation Fuel Performance Code Conceptual Design}

Gregory K. Miller

Pavel G. Medvedev

March 2007

Idaho National Laboratory

Idaho Falls, Idaho 83415

Prepared for the

U.S. Department of Energy

Office of Nuclear Energy

Under DOE Idaho Operations Office

Contract DE-AC07-05ID14517 


\section{CONTENTS}

1. PURPOSE OF THE TRANSMUTATION FUEL PERFORMANCE CODE ............................... 1

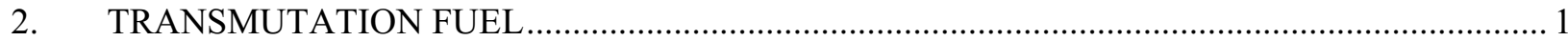

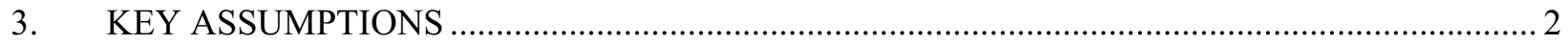

4. USE OF FRAPCON-3 AS A CHASSIS FOR THE TRANSMUTATION FUEL

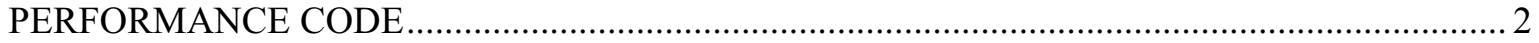

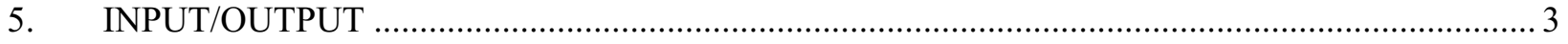

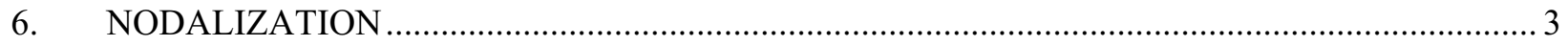

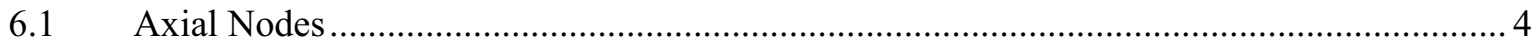

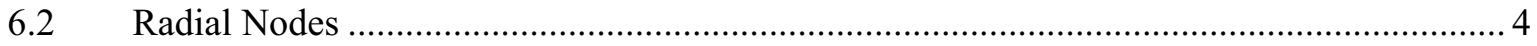

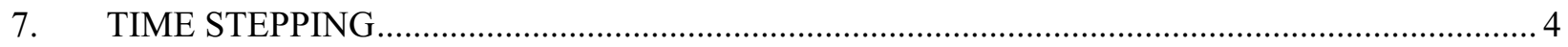

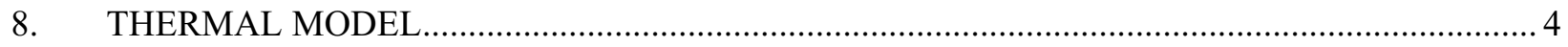

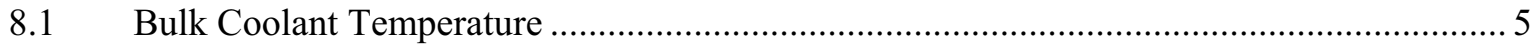

8.2 Heat Transfer from Coolant to Cladding .................................................................. 5

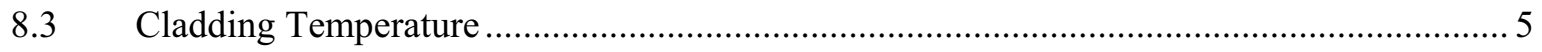

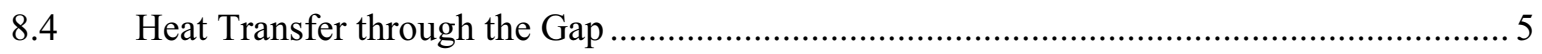

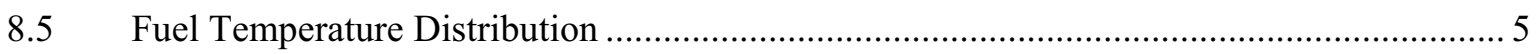

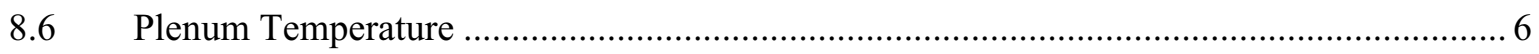

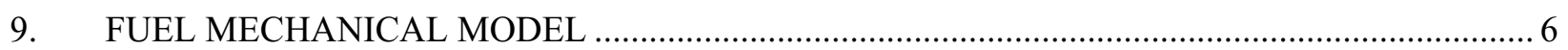

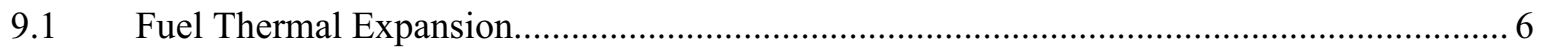

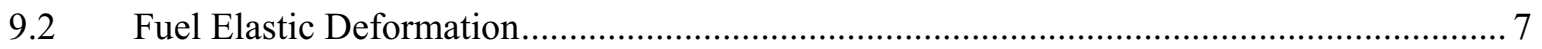

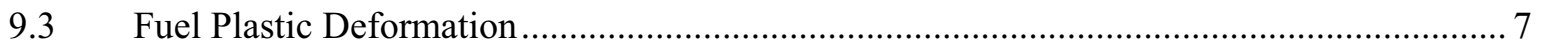

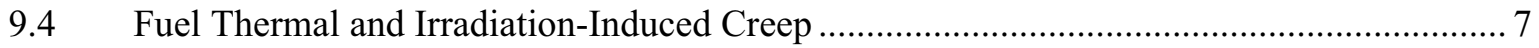

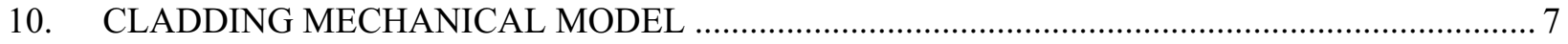

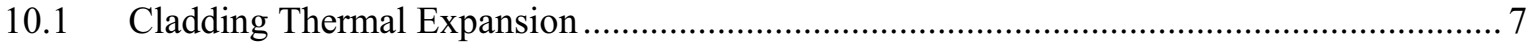

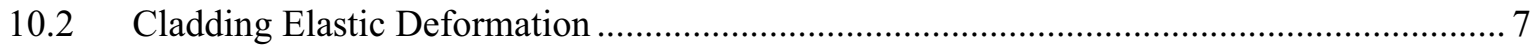

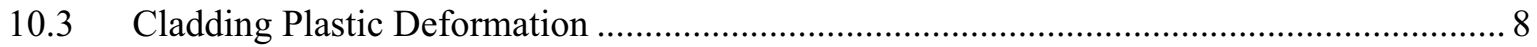


10.4 Cladding Thermal and Irradiation-Induced Creep.................................................. 8

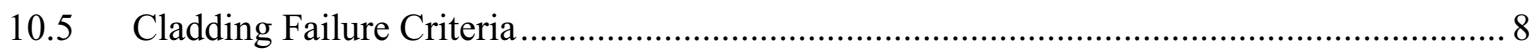

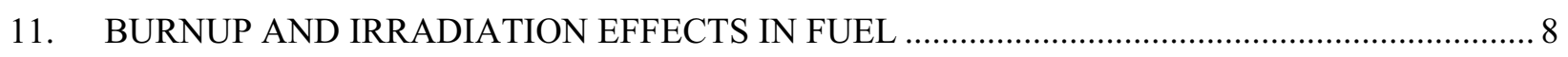

11.1 Actinide and Fission Product Inventory …............................................................ 8

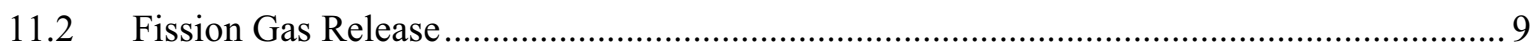

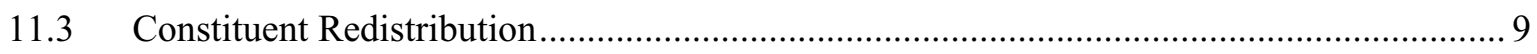

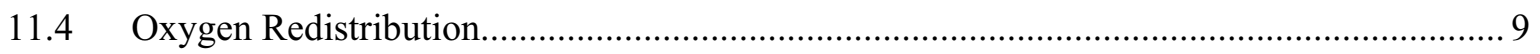

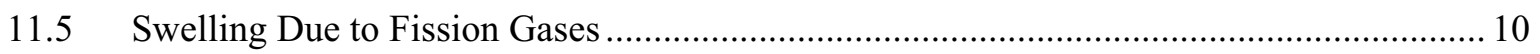

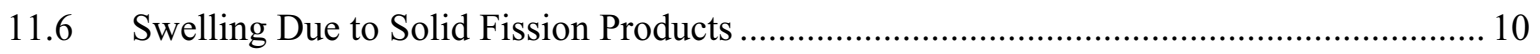

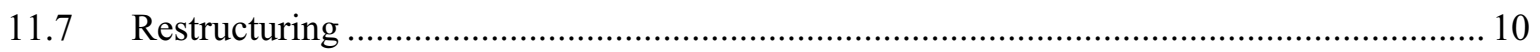

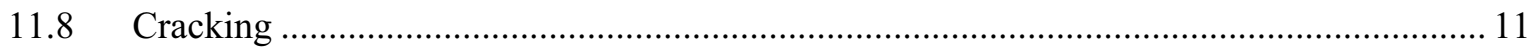

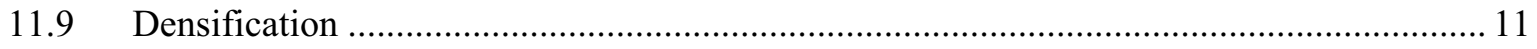

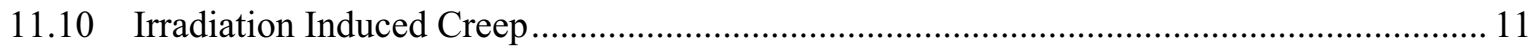

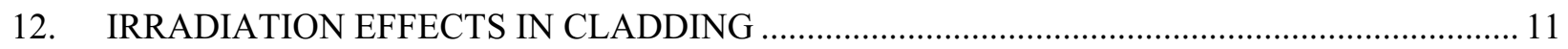

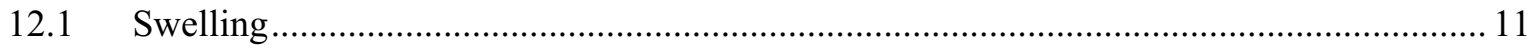

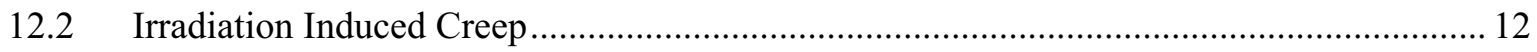

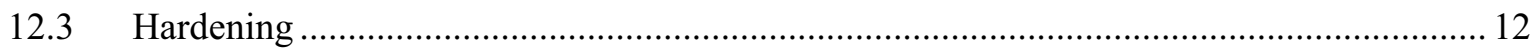

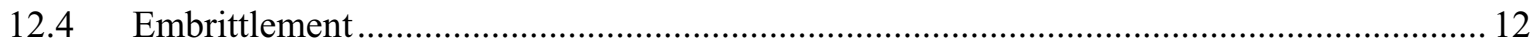

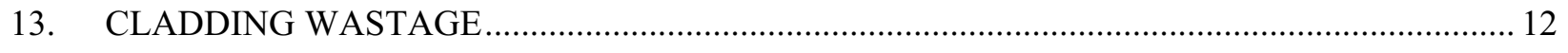

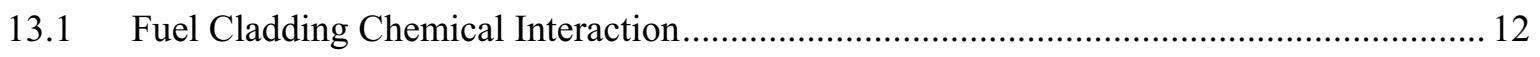

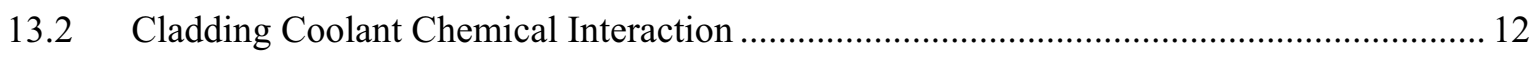

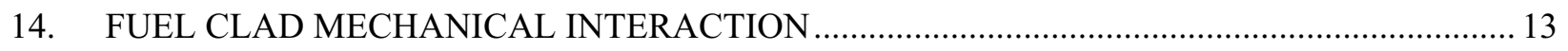

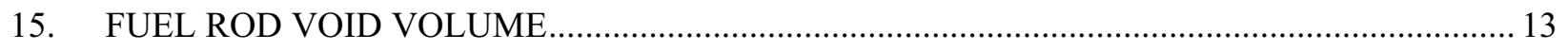

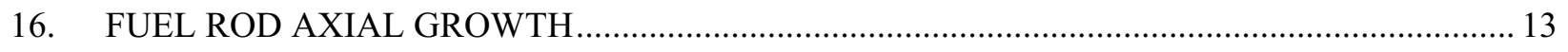

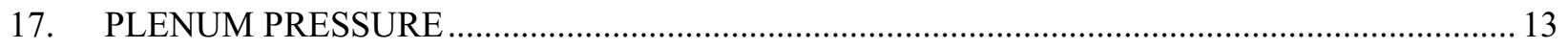




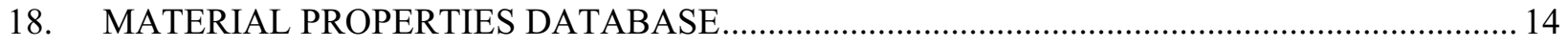

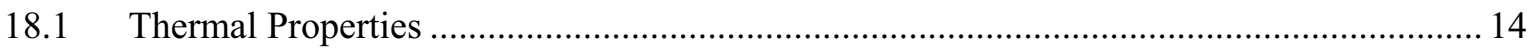

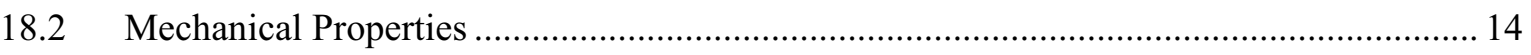

18.3 Property Degradation with Burnup and Fluence ...................................................... 14

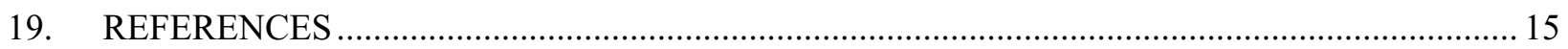

TABLES

Table 1. Key features of MOX and metallic transmutation fuel elements.............................................. 2 


\title{
TRANSMUTATION FUEL PERFORMANCE CODE CONCEPTUAL DESIGN
}

\section{PURPOSE OF THE TRANSMUTATION FUEL PERFORMANCE CODE}

\begin{abstract}
One of the objectives of the Global Nuclear Energy Partnership (GNEP) is to facilitate the licensing and operation of Advanced Recycle Reactors (ARRs) for transmutation of the transuranic elements (TRU) present in spent fuel. A fuel performance code will be an essential element in the licensing process ensuring that behavior of the transmutation fuel elements in the reactor is understood and predictable. Even more important in the near term, a fuel performance code will assist substantially in the fuels research and development, design, irradiation testing and interpretation of the post-irradiation examination results.
\end{abstract}

The ultimate goal of the nuclear fuel behavior modeling is to predict the length of time that the cladding performs its primary function of separating the coolant from the fuel given the geometry of the fuel element, the initial materials properties of the fuel and cladding, and the fuel pin power history. Historically, the nuclear industry has relied on fuel performance codes to model fuel behavior in nuclear reactors.

A fuel performance code follows the evolution of the mechanical, chemical, metallurgical and thermal state of the fuel and cladding from the beginning to the end of life of the fuel pin. Essential elements of the fuel performance code are the driver, subroutines and materials properties database. The driver controls the sequence of the calculations performed by the code and transfers data between the subroutines, the subroutines model particular processes, and the materials properties database generates numerical values describing specific properties of fuel and cladding at a given moment. The models and materials properties database are either based on theory or derived from experimental data.

\section{TRANSMUTATION FUEL}

Within the current GNEP scope, transmutation fuel is a nuclear reactor fuel destined for consumption in fast spectrum sodium-cooled ARRs. The closed fuel cycle technology envisioned by GNEP employs ARRs to transmute the stream of transuranic elements such as plutonium, americium, neptunium and curium evolving from the recycling of spent nuclear fuel. Depending on the recycling process, rare earth fission products may also be present in the fresh fuel.

With the exception of the fuel composition, transmutation fuel element design is identical to the established designs of fast reactor fuels. Because both ceramic mixed oxide (MOX) and metallic alloy fuel options may be utilized in ARR, the transmutation fuel performance code will have the capability to analyze each of these options. 
Main characteristics of MOX and metallic transmutation fuel elements are outlined in Table 1. These constitute key input data required for the fuel performance analysis.

Table 1. Key features of MOX and metallic transmutation fuel elements.

\begin{tabular}{|l|l|l|}
\hline \multicolumn{1}{|c|}{ Parameter } & \multicolumn{1}{|c|}{$\mathrm{MOX}$} & \multicolumn{1}{c|}{ Metallic alloy } \\
\hline Fresh fuel constituents & $\begin{array}{l}\mathrm{UO}_{2}, \mathrm{PuO}_{2}, \mathrm{AmO}_{2}, \\
\mathrm{NpO}_{2}, \mathrm{CmO}_{2}, \mathrm{La}_{2} \mathrm{O}_{3}, \\
\mathrm{Pr}_{2} \mathrm{O}_{3}, \mathrm{CeO}_{2}, \mathrm{Nd}_{2} \mathrm{O}_{3}\end{array}$ & $\begin{array}{l}\mathrm{Zr}, \mathrm{U}, \mathrm{Pu}, \mathrm{Am}, \mathrm{Np}, \\
\mathrm{Cm}, \mathrm{La}, \mathrm{Pr}, \mathrm{Ce}, \mathrm{Nd}\end{array}$ \\
\hline Fuel form & Sintered ceramic pellet & Cast alloy slug \\
\hline Cladding & \multicolumn{2}{|c|}{ Stainless steel tube } \\
\hline Fuel-cladding bond & $\mathrm{He}$ & $\mathrm{Na}$ \\
\hline Peak linear power, W/cm & \multicolumn{2}{|c|}{450} \\
\hline Target burnup, at. \% & \multicolumn{2}{|c|}{$>20$} \\
\hline
\end{tabular}

\section{KEY ASSUMPTIONS}

Key assumptions that will be used in development of the new coding are:

- Steady state conditions exist during each time step

- Small changes in power between time steps are allowed

- Small cladding ( $<5 \%$ strain) deformations are allowed

- No heat transfer occurs in the axial direction of the fuel pin

- Thermal, mechanical, and fission gas release behavior in the fuel pin are treated as symmetric in the azimuthal direction.

\section{USE OF FRAPCON-3 AS A CHASSIS FOR THE TRANSMUTATION FUEL PERFORMANCE CODE}

The basic modeling approach will be to modify the existing FRAPCON- $3^{1}$ fuel performance code as necessary to accommodate both oxide and metallic fuels operating in a fast reactor. FRAPCON-3 is an established code that is continuously maintained, and has an experienced user community. The code was prepared for the US Nuclear Regulatory Commission for use in licensing of commercial light water reactors (LWRs). Using an existing code framework will accelerate progress in development of a transmutation fuel code. The modular structure of FRAPCON-3 facilitates the process of making modifications or additions to existing components of the code. A large database of material properties are contained in subroutines that collectively comprise what is called MATPRO. Obviously, numerous modifications to the code will be needed, because of the significant differences between a fast reactor, using either oxide or metal fuel with a liquid sodium coolant, and an LWR using only oxide fuel with a water coolant. 
This code will be structured so that the capability to consider transmutation fuels will be added to (rather than replace) the existing capabilities of the code. Therefore, the capability to consider an oxide fuel with zircaloy cladding and water coolant will be retained. Nonapplicable features will simply be turned off when a transmutation fuel rod is evaluated.

An option may be provided to perform finite element analysis to capture multi-dimensional mechanical response in a fuel rod. For example, hour-glassing of a fuel pellet may cause non-uniform contact of the fuel with the cladding, which can only be captured with multi-dimensional analysis. Three basic alternatives for adding finite element analysis capability to the code are: 1) linking to a commercial program such as ABAQUS, 2) incorporating finite element analysis capability from another fuel performance modeling code, or 3) developing this capability from scratch. The first of these approaches is probably the most practical, but relies on the user having a license to the commercial program. One-dimensional analysis capability, as contained in FRAPCON-3, will be retained so that the code can still be readily used by persons not versed in finite element analysis.

\section{INPUT/OUTPUT}

The current structure for providing input to the FRAPCON-3 code will be utilized in the new code. Input parameters for a specific fuel rod are provided in an input file via a namelist. Indices will be added that serve to indicate when a transmutation fuel rod and liquid sodium coolant are to be analyzed. Many input parameters currently used, such as inlet temperature and mass flux of the coolant, dimensions, time steps, fuel rod pitch, heat flux profile, and power history will continue to be used as is. Additional parameters unique to a transmutation fuel rod will be contained in a new namelist that will be used for this type of fuel rod only. As is currently done, new material properties and correlations will be hardwired into the code rather than supplied as user input.

The current structure for producing output from the code will also be retained. Output such as radial temperatures, cladding stresses, geometry changes, void volume, gap conductance, interface pressure, gas pressure, densification, swelling, time step information, etc., can be printed out at the end of each time step for each axial region in the model and can be plotted directly using the graphics capability existing in the current version of the FRAPCON-3. New output that is of interest for this type of fuel rod will be added as appropriate.

\section{NODALIZATION}

Temperatures in the fuel and cladding are calculated in the thermal model at discrete nodal locations across the radius of the fuel pin and along the axis of the fuel. This enables the calculation of a radial temperature distribution from the center (axis) of the fuel to the coolant. No heat transfer is assumed to occur in the fuel or cladding in the axial direction, but the heat flux and coolant temperature vary with height. Due to these variations, temperature distributions are calculated at a number of nodal locations along the axis of the fuel. The fuel pin will be assumed to have azimuthal symmetry, so the temperatures vary only in the radial and axial directions.

Temperatures calculated at the various nodal locations are used as input to the mechanical model, so that stresses and displacements can be calculated in the cladding and fuel. In the mechanical model, stresses and deformations in the fuel and cladding will be calculated at discrete nodal locations (probably the same as those used in the thermal model). 


\subsection{Axial Nodes}

As noted above, a radial temperature distribution and corresponding stresses and displacements will be calculated at each axial nodal location in the model. The number of and location of the axial nodes at which temperatures and deformations are calculated will be at the discretion of the user, and will be provided in the user input.

\subsection{Radial Nodes}

In the thermal and mechanical models, the fuel will be divided into several annular regions since the thermal and mechanical properties vary through the thickness of the fuel. The material properties are assumed to be uniform within each region. Initially, the variable nodal meshing used for the fuel in FRAPCON-3, which is based on a model developed at the Institute for Transuranium Elements, Karlsruhe, ${ }^{2}$ will be utilized. The meshing scheme places a greater density of nodes near the outer surface of the fuel. This can be readily modified if needed, which will depend on how it behaves with the transmutation fuel. In any case, the first node will be located at the fuel centerline or inner surface of the fuel and the last node will be located at the outer surface of the fuel. The number of radial nodes is at the discretion of the user, and is provided as user input. The remaining annular regions in the model, i.e. the gap and cladding, will each be treated as a single annular region with uniform properties. Therefore, the nodes at which temperatures and deformations are calculated for these regions are the inner and outer surfaces of the cladding. Convective heat transfer to the coolant occurs at the outer surface of the cladding. Therefore, the outermost node in the thermal model is a node that represents the coolant. This node is not used in the mechanical model.

\section{TIME STEPPING}

The power, burnup, and material properties vary through the lifetime of the fuel rod. As such, the temperatures, stresses, displacements, and internal gas pressure in the fuel rod are calculated in finite time steps. Within each time step, the solutions for temperatures, deformations, fuel swelling, and internal gas pressure are iterated until convergence is reached. Convergence criteria for calculated temperatures, swelling, gas pressure, and strains will be controlled within the program, and therefore not be affected by user input. Accuracy of the solution at the end of a time step is also affected by the size of the step, which will be at the discretion of the user. It is expected, though, that the program will make internal checks and provide warning messages if a selected time step is not suitable for reaching convergence or acceptable accuracy.

\section{THERMAL MODEL}

The thermal model is used to calculate the temperature distribution through the fuel and cladding at axial nodes throughout the height of the fuel. It is also used to calculate the temperature in the plenum region above the fuel. Temperatures will be calculated at 1) radial locations throughout the fuel, including its outside surface, 2) the inside and outside surfaces of the cladding, 3) the coolant, and 4) the plenum region above the fuel. Assuming symmetry about the fuel axis, a one-dimensional model will be used to calculate temperatures. Temperature distributions will be calculated at axial nodes along the height of the fuel. Because it is assumed that no heat conduction occurs in the axial direction, a one-dimensional temperature distribution will be determined at each of these axial nodes. 


\subsection{Bulk Coolant Temperature}

The bulk coolant temperatures along the height of the fuel rod will be calculated assuming a single, closed coolant channel. The mass flux and coolant heat capacity will correspond to a liquid sodium coolant.

\subsection{Heat Transfer from Coolant to Cladding}

Convective heat transfer for a liquid sodium coolant will be assumed in determining the cladding surface temperature. It is planned to use the Borishanskii, Gotovskii, and Firsova correlation ${ }^{3}$ for the convective heat transfer coefficient because it agrees well with experimental data for liquid sodium.

\subsection{Cladding Temperature}

The temperature drop across the cladding will be calculated assuming steady-state conduction heat transfer through a cylinder with a uniform thermal conductivity representing that of stainless steel. A thermal conductivity correlation for stainless steel will be added to MATPRO.

\subsection{Heat Transfer through the Gap}

For metallic fuel, the temperature drop across the gap between the fuel and cladding will be calculated using a gap conductance corresponding to the liquid sodium in the gap region. The conductance will represent the effects of conductive heat transfer through the liquid sodium and contact conductance between the fuel and cladding for situations where the fuel and cladding make contact. The gap conductance will account for thermal conductivities of the fuel, liquid sodium, and cladding used in the modeled fuel. The conductance for solid-solid contact will be based on data appropriate for stainless cladding. Unlike the gas gap in FRAPCON-3, no radiation heat transfer from the fuel to cladding will be included.

In oxide fuel, the gap between the fuel and cladding is occupied by gas. The temperature drop across the gap will be calculated as in FRAPCON-3. The calculation will include the effects of conductive heat transfer through the gas and contact conductance between the fuel and cladding when the fuel and cladding make contact. In addition, the effect of radiation heat transfer from the fuel to the cladding will be included.

\subsection{Fuel Temperature Distribution}

The temperature distribution across the radius of the fuel will be determined assuming steady-state heat conduction through the fuel. The temperatures will be calculated at several nodes across the radius using either the finite-difference approach as used in FRAPCON-3, or with a closed-form solution to the heat conduction equation. The source term in the equation will be based on an axial power function representative of the fuels modeled. The thermal conductivity of the fuel will be treated as a function of both temperature and spatial location in the fuel. 


\subsection{Plenum Temperature}

The temperature of the plenum region has a significant effect on the internal pressure for the fuel rod. The plenum temperature is generally just a few degrees higher than the coolant temperature in the region above the fuel. Therefore, the development of a new complex model to calculate the plenum temperature is not warranted. For completeness, though, a model should be available in the code that calculates this temperature for purposes of fuel design. The most expedient approach is to adopt the model currently contained in the FRAPTRAN code, ${ }^{4}$ but applied to steady-state rather than transient conditions. Using this model, the temperature calculated for the plenum region will account for the potential effects of 1) free convective heat transfer to the gas from the surfaces of the liquid sodium (or fuel), cladding, and hold-down spring, 2) conductive heat transfer in the spring and cladding, 3) gamma heating of the spring and cladding, 4) radiation heat transfer between the spring and cladding. If it is determined that this model is more detailed that necessary, it can be readily simplified. Heat transfer correlations in the model will be adjusted as needed.

Iteration is required in the thermal model at each time step, so that material properties are consistent with the temperatures calculated. Also, results must be communicated between the temperature, deformation, and gas pressure models at each time step, so that the temperatures, gap size, and gas pressure converge at each step.

\section{FUEL MECHANICAL MODEL}

A mechanical model will be included in the code to determine deformations of the fuel. Deformations of the fuel include the effects of fuel thermal expansion, swelling, densification, and restructuring. For metallic fuel, the model will also allow for elastic, plastic, and creep behavior of the fuel caused by internal pressure, temperature variations, and potential contact with the cladding.

The rigid-fuel model of FRACAS-I (currently contained in FRAPCON-3) will be utilized for situations where elastic, plastic, and creep deformations of the fuel are deemed to be minor. This model calculates axial and radial displacements, crack volume, and porosity of the fuel. It assumes that thermal expansion (with swelling and densification) and fuel restructuring are the only sources of fuel deformation, and that the cladding provides no resistance to the fuel expansion.

The deformable-fuel model of FRACAS-II will be utilized for situations where elastic, plastic, and creep deformations of the fuel are deemed to be important, which is most likely to be the case for metallic fuels. This model calculates stress and strain distributions in both the fuel and cladding.

\subsection{Fuel Thermal Expansion}

Thermal expansion of the fuel affects the size of the gap between the fuel outer surface and cladding inner surface. This in turn affects the temperature drop across the gap and can contribute toward mechanical interaction between the fuel and cladding. If interaction occurs, then differential thermal expansion between the fuel and cladding affects the magnitude of stresses in the cladding and fuel. This will be accounted for by including a thermal expansion strain component in the total strain of the fuel in each of three coordinate directions. Appropriate thermal expansion coefficients will be added to the MATPRO subroutines. 


\subsection{Fuel Elastic Deformation}

An elastic strain component will be included in the total strain of the fuel in each of three coordinate directions. Elastic deformation will be assumed to be isotropic and will be characterized by an elastic modulus and Poisson's ratio. These properties of the fuel, which will likely vary through the thickness of the fuel, will be added to the MATPRO subroutines.

\subsection{Fuel Plastic Deformation}

Plastic deformation of the fuel can occur once stresses in the fuel exceed the yield strength. Plastic deformation will be based on a stress-strain curve representative of the fuel. Yielding of the material will be determined according to the Von Mises yield criterion. Plastic strain components will be included in the total strain of the fuel in each of three coordinate directions. The plastic strain increments (which are constant volume) in each coordinate direction will be determined using the Prandtl-Reuss flow rule.

\subsection{Fuel Thermal and Irradiation-Induced Creep}

When stresses in the fuel become significant, they may drive a time-dependent creep response in the fuel. Creep behavior in the fuel can be induced by both high temperature and neutron fluence. Creep strain components will be included in the total strain of the fuel in each of three coordinate directions. As with plasticity increments, the constant-volume creep strain increments will be determined using the Prandtl-Reuss flow rule. If applicable, the creep strain increments will also include a component of volumetric strain. A creep law appropriate for thermal creep in metallic fuel will be added to the MATPRO subroutines for the constant-volume strain rate. Likewise, a creep law will be added for the volumetric strain rate due to thermal creep if needed. Corresponding creep laws for irradiation-induced creep will be added to MATPRO subroutines. The creep strains caused by thermal and irradiation-induced creep will be combined in the stress analysis of the cladding.

\section{CLADDING MECHANICAL MODEL}

The cladding mechanical model will be used to calculate elastic, plastic, and creep deformations of the cladding that are caused by internal and external pressures, temperature variations, and potential contact with the fuel.

\subsection{Cladding Thermal Expansion}

Thermal expansion of the cladding affects the size of the gap between the fuel outer surface and cladding inner surface. This in turn affects the temperature drop across the gap, and the time at which mechanical interaction between the fuel and cladding occurs. If interaction occurs, then differential thermal expansion between the fuel and cladding affects the magnitude of stresses in the cladding and fuel. This will be accounted for by including a thermal expansion strain component in the total strain of the cladding in each of three coordinate directions. Appropriate thermal expansion coefficients will be added to the MATPRO subroutines.

\subsection{Cladding Elastic Deformation}

An elastic strain component will be included in the total strain of the cladding in each of three coordinate directions. Elastic deformation will be assumed to be isotropic and will be characterized by an elastic modulus and Poisson's ratio. These properties of the stainless steel cladding will be added to the MATPRO subroutines. 


\subsection{Cladding Plastic Deformation}

Plastic deformation of the cladding will occur once stresses in the cladding exceed the yield strength. Plastic deformation will be based on a stress-strain curve representative of the stainless steel cladding. Yielding of the material will be determined according to the Von Mises yield criterion. Plastic strain components will be included in total strain of the cladding in each of three coordinate directions. The plastic strain increments (constant volume) in each coordinate direction will be determined using the Prandtl-Reuss flow rule.

\subsection{Cladding Thermal and Irradiation-Induced Creep}

When stresses in the cladding become significant, they drive a time-dependent creep response in the cladding. Creep behavior in the cladding can be induced by high temperature and/or irradiation (neutron fluence). Creep strain components will be included in the total strain of the cladding in each of three coordinate directions. As with plasticity increments, the constant-volume creep strain increments will be determined using the Prandtl-Reuss flow rule. If applicable, the creep strain increments will also include a component of volumetric strain. A creep law appropriate for thermal creep in stainless steel will be added to the MATPRO subroutines for the constant-volume strain rate. Likewise, a creep law will be added for the volumetric strain rate due to thermal creep if needed. Corresponding creep laws for irradiation-induced creep will also be added to the MATPRO subroutines as needed. The creep strains caused by thermal and irradiation-induced creep will be combined in the stress analysis of the cladding.

\subsection{Cladding Failure Criteria}

Fracture of the cladding constitutes failure of the fuel rod. Therefore, a failure criterion will be added to the model. Creep rupture, fatigue caused by thermal cycles, and thermal ratcheting are potential failure mechanisms for the cladding. The code will likely employ a cumulative damage approach to include the effects of each of these mechanisms. The damage fraction due to creep rupture is measured in terms of the ratio between the time duration at a given stress level and the time at which creep rupture would occur at that stress level. The damage fraction due to fatigue from thermal cycles is measured in terms of the ratio between the number of cycles at a given stress level and the number of cycles at which fatigue failure would occur at that stress level. Finally, the damage fraction due to ratcheting is measured in terms of the ratio between the inelastic strain that accumulates with thermal cycles (occurring in combination with pressure loading or mechanical interaction) and the failure strain. This requires that time-to-rupture criteria, fatigue failure curves, and strain limit criteria be incorporated in the code.

\section{BURNUP AND IRRADIATION EFFECTS IN FUEL}

\subsection{Actinide and Fission Product Inventory}

A new depletion model capable of tracking isotopes of interest in each fuel node in the fast reactor neutron spectrum will be incorporated in the code. The model will calculate fission density from the fuel pin linear power, radial and axial power profiles. Quantities of the isotopes of interest will be calculated from fission density and respective fission yields. 


\subsection{Fission Gas Release}

FRAPCON-3 uses the MASSIH fission gas release model derived from the Booth diffusion model. The model may need further revision to accommodate a fast reactor environment. Above a threshold burnup of about $100 \mathrm{MWd} / \mathrm{kgM}$ in a fast breeder reactor, it can be expected that essentially all of the fission gas in a mixed-oxide (MOX) fuel is released. ${ }^{5}$

In the metallic fuel fission gas bubbles nucleate and grow at a much higher rate than in ceramic $\mathrm{UO}_{2}$ fuel, due to the high diffusivity of fission gas atoms in the metallic fuel. In metallic fuel fission gas bubbles could nucleate at the phase boundaries inside the grain as well as at the grain boundaries. The effect of grain size on fission gas behavior may not be significant compared with its effect in $\mathrm{UO}_{2}$ fuel. To realistically address the formation and behavior of gas bubbles, gas diffusion, and the effect of contact pressure due to fuel gap closure, mechanistic models such as those of, ${ }^{6,7}$ will be considered for incorporation into the code for fission gas release in metallic fuel.

\subsection{Constituent Redistribution}

In the oxide fuel the large temperature gradients and the communication between regions of differing temperature in the fuel (made possible by cracks and interconnected porosity) facilitate the transport of heavy metals. The transport of heavy metals in an oxide fuel is referred to as actinide redistribution. Actinide redistribution tends to concentrate the actinides toward the center of the fuel pin. This results in a larger separation between the heat source and heat sink, and therefore a higher temperature in the center. This means a sacrifice in linear power to keep the central temperature below the melting temperature. The principal mechanisms for actinide redistribution are 1) thermal diffusion of plutonium, and 2) vapor migration of gaseous uranium species. Appropriate diffusion and vapor transport models will be incorporated in the code to represent these mechanisms.

Metallic fuel is prone to radial redistribution of alloy constituents by solid-state diffusion under thermal and chemical potential gradients. The diffusion process is enhanced by fission. Redistribution may be rapid and severe resulting in formation of new phases in the fuel, sometimes even at low burnup. This affects thermal performance of the pin due to local changes in thermal conductivity and solidus of the fuel. To account for this phenomenon, a constituent redistribution model such as described in ${ }^{8}$ will be considered for incorporation into the code.

\subsection{Oxygen Redistribution}

The transport of oxygen in an oxide fuel is referred to as oxygen redistribution. Oxygen redistribution is important to fuel modeling because fuel properties, such as thermal conductivity and creep, are dependent on the oxygen-metal $(\mathrm{O} / \mathrm{M})$ ratio. An appropriate model will be incorporated into the code to represent the oxygen diffusion. 


\subsection{Swelling Due to Fission Gases}

During the fission process, about $15 \%$ of the fission products occur as the rare gases xenon and krypton. These gases initially collect as small bubbles within the grains or as large bubbles along the grain boundaries, contributing to fission gas fuel swelling. Swelling of the fuel affects the size of the gap between the fuel outer surface and cladding inner surface, the temperature drop across the gap (and therefore the temperature in the fuel), and the time at which mechanical interaction between the fuel and cladding occurs. This will be accounted for by including a swelling strain component in the total strain of the fuel in each of three coordinate directions. The fuel swelling caused by fission gases will be determined in the fission gas release model. Because bubble swelling is affected by the contact pressure between the fuel and cladding and vice versa, the calculation of fuel swelling will be part of the iteration loop in each time step that reaches a convergent solution for temperature, deformation, fuel swelling, and gas pressure.

\subsection{Swelling Due to Solid Fission Products}

Most of the fission products in a fast reactor lodge within the fuel matrix as solid particles, contributing to fission product fuel swelling. This will be included in the swelling strain component of the total fuel strain. It is then included in the fuel swelling calculation in the iteration loop that is exercised with each time step.

\subsection{Restructuring}

Because of the higher temperatures and steep temperature gradients in the fuel of a fast reactor, substantial alterations in the morphology of the fuel material take place during power operation. In oxide fuel, a central void region develops because of the migration of pores up the steep temperature gradient in the central region of the fuel. Adjacent to the void is a solid region of high temperature gradient, characterized by large columnar grains that result from the pore migration. This is a region of fuel densification (reduction of void volume). The next region contains a band of large equiaxed grains, where the original fine grains have grown to many times their original size. In the outer region, where fuel temperatures are lowest, the fuel still has its original microstructure. As a result of this restructuring, the densities, thermal properties, and mechanical properties may significantly differ in these annular regions of the fuel. This will be accounted for in the thermal, deformation, and gas release models of the fuel, where the properties will be varied accordingly across the radius of the fuel.

Metallic fuels experience an infiltration of the sodium bond following the large volume increase due to swelling and a resultant network of interconnected porosity. The release of fission product gas opens porosities that are infiltrated by the sodium because of its high capillarity. The replacement of fission product gas with sodium serves to recover, to a degree, the degraded thermal conductivity of the fuel. This effect will be accounted for in the thermal models. 


\subsection{Cracking}

The temperature gradient across the fuel leads to tangential stresses in the outer region of the fuel that exceed the fracture strength of the fuel material. This leads to radial cracks in the fuel, particularly in the outer region where the fuel is more brittle. These cracks tend to develop early before swelling and creep have much effect, so are essentially the result of thermoelastic behavior. The cracks can be predicted in the model by comparing tensile stresses in the fuel with a fracture strength for the fuel. The cracks are a form of open porosity in the fuel, so will affect fission gas release. This effect will be included in the gas release model. The voids created by the cracks force an outward movement of the fuel that affects the size of the gap. An approximate calculation will be made in the code for the outward displacement $\Delta R$ resulting from the cracks. The cracks also tend to soften the fuel, thereby affecting stresses in the fuel. This will be accounted for by making adjustments to the fuel stiffness (Young's modulus) and Poisson's ratio in the constitutive equations for the cracked portion of the fuel.

\subsection{Densification}

During irradiation of the oxide fuel, some of the porosity is removed by the disruptive action of fission fragments passing through or near pores. This process, called densification, can lead to a reduction in volume of the fuel, and hence a lower contact pressure between the fuel and cladding. Densification is represented by a diffusion equation for the transport of vacancies from pores within a grain to the grain boundary. Because of the higher fuel temperatures in a liquid-metal fast reactor, the modeling of this process will have to modified from what is used for a light water reactor. The primary effect, though, is a reduction in fuel radius, which will be accounted for in the strain calculation in the deformation model.

\subsection{Irradiation Induced Creep}

Irradiation may induce a creep response in metallic fuel. Irradiation-induced creep deformations will be considered by applying a creep law that appropriately represents such creep in metallic fuel. The creep rate is generally a function of temperature. Creep deformation of the fuel, if it occurs, becomes significant when the stress in the fuel reaches a meaningful level. This may occur if there is significant internal pressure or if the fuel contacts the cladding.

\section{IRRADIATION EFFECTS IN CLADDING}

\subsection{Swelling}

It has been observed that void swelling of stainless steel cladding can occur under high fluence conditions. The extent of the swelling is strongly a function of temperature, and could well occur in the operating range of a liquid metal fast reactor. As with thermal expansion, swelling of the cladding would affect the size of the gap between the fuel outer surface and cladding inner surface, the temperature drop across the gap, and the time at which mechanical interaction between the fuel and cladding occurs. This will be accounted for by including a swelling strain component in the total strain of the cladding in each of three coordinate directions. An appropriate correlation will be added to the MATPRO subroutines. 


\subsection{Irradiation Induced Creep}

Irradiation-induced creep deformations will be considered by applying a creep law that appropriately represents such creep in stainless steel cladding. The creep rate is generally a function of temperature. A creep strain component will be included in the total strain for the cladding in each of three coordinate directions. The potential for irradiation-induced creep to lead to creep rupture will be considered in the failure criteria for the cladding (see below).

\subsection{Hardening}

Irradiation causes hardening of the stainless steel cladding, i.e. it increases the yield strength of the material. To a lesser extent it also increases the ultimate strength of the steel. The degree of hardening is dependent on the irradiation temperature, i.e. higher temperatures tend to mitigate the hardening effect. Radiation hardening will be accounted for in the mechanical model by adjusting the stress-strain curve accordingly.

\subsection{Embrittlement}

Neutron irradiation also embrittles (reduces the ductility) stainless steel cladding. Furthermore, the production of helium above $500^{\circ} \mathrm{C}$ significantly decreases both the strength and ductility of stainless steel cladding. The extent of helium embrittlement depends on fast-neutron fluence, steel composition, and temperature. These embrittlement effects will be accounted for in the mechanical model (stress-strain curves) and in the failure criteria (see below) for the cladding.

\section{CLADDING WASTAGE}

\subsection{Fuel Cladding Chemical Interaction}

Corrosion of the cladding by chemical reactions with the fuel and fission products can decrease the cladding thickness. Any reduction in cladding thickness will be tracked at each time step and accounted for in the mechanical model of the cladding. The reduction in cladding thickness can result in higher stresses and a shorter time to rupture.

\subsection{Cladding Coolant Chemical Interaction}

Flowing high-temperature sodium slowly dissolves the major metallic components (iron, chromium, and nickel) of the stainless steel, which also results in wastage, or thinning, of the cladding. This reduction in cladding thickness will be tracked at each time step and accounted for in the mechanical model of the cladding. Again, a reduction in cladding thickness can result in a shorter time to rupture. 


\section{FUEL CLAD MECHANICAL INTERACTION}

As discussed above, thermal expansion and swelling of the fuel can lead to contact (mechanical interaction) between the fuel and cladding. The fuel and cladding are analyzed individually before contact occurs. Contacting cylinders are used to analyze the fuel and cladding after fuel expansion results in contact. In this model, the cladding will be treated as a single-layer cylinder with uniform properties through its thickness. Because the model of the fuel allows for a radial variation in material properties, though, the fuel will be divided into annular regions, and the finite difference approach will be used to determine stresses and strains in the fuel. A condition of compatible displacements and radial stresses at the interface between the two cylinders will be applied in the model.

The deformation of the fuel and cladding will affect the solid-solid conductance between the two materials, which will be reflected in the thermal analysis.

\section{FUEL ROD VOID VOLUME}

The internal gas pressure in the fuel rod depends on the fuel rod void volume. The voids that contribute to the total void volume in a fuel rod include 1) the interface volume between fuel pellets, 2) the fuel-cladding gap volume in oxide fuels, 3) the fuel crack volume which results from high thermal stresses, 4) the plenum volume, and 5) open porosity. These volumes can change with time, so will be calculated at each time step, and the new values will be used in the pressure calculation at each step.

\section{FUEL ROD AXIAL GROWTH}

Fuel rod axial growth is an important factor because it affects the fuel assembly support and constraint designs. Void swelling in the cladding is the primary source of axial growth. Fuel-cladding mechanical interaction can also contribute to rod elongation by promoting plastic strain and enhanced creep. The total fuel rod axial growth will be calculated in the deformation model, by accumulating the deformations calculated for the axial regions in the model.

\section{PLENUM PRESSURE}

Fission gas released from the fuel matrix collects in several fuel rod void volumes, the largest of which is the plenum region above the fuel. As in FRAPCON-3, the ideal gas law will be applied to a multiple volume region in calculating the pressure in the plenum. The fission gas release, fuel void volumes, and void volume temperatures calculated at each time step will be used in this law to calculate the new value for pressure at the step. The pressure calculation will be iterated along with the temperature and deformation calculations until the calculated pressure meets convergence criteria. The convergence criteria will be built into the program. 


\section{MATERIAL PROPERTIES DATABASE}

In FRAPCON-3, a large database of material properties are contained in a library of subroutines called MATPRO. This database will be extended as necessary to incorporate material properties for the fuel, cladding, and coolant in the fast reactor.

\subsection{Thermal Properties}

Thermal properties such as specific heats and thermal conductivities of liquid sodium, stainless steel cladding, and the metal or oxide fuels will be added to appropriate subroutines of the code.

\subsection{Mechanical Properties}

Mechanical properties such as stress-strain curves, creep laws (including that for volumetric creep strain), thermal expansion coefficients, Poisson's ratio, swelling correlations, and other deformation characteristics that are appropriate for the metal fuel and stainless steel cladding will be added to MATPRO.

\subsection{Property Degradation with Burnup and Fluence}

Many of the material properties of the fuel and cladding can be influenced by neutron fluence as irradiation proceeds. As discussed above, fluence can induce creep response in these materials. This may relieve stresses in the material, but contribute to large deformations that lead to early rupture. Irradiation also contributes to hardening and embrittlement of the materials, which affects their deformation and the strain levels at which the materials fracture. Irradiation hardening may also affect the time at which the cladding may rupture when experiencing thermal creep. The thermal conductivity of the fuel decreases with burnup due to the material density loss. The general approach to modeling these effects in the code is to adjust material properties based on best available data obtained from experimental results. The code must be flexible in allowing for modifications to accommodate data that becomes available in the future. 


\section{REFERENCES}

1. FRAPCON-3: A Computer Code for the Calculation of Steady-State, Thermal-Mechanical Behavior of Oxide Fuel Rods for High Burnup, NUREG/CR-6534, Vol. 2, PNNL-11513, 1997

2. K. Lassman, C. O'Carrol, J. VanderLaar, and C. T. Walker, "The Radial Distribution of Plutonium in High Burnup UO2 Fuels," J. Nuclear Materials, Vol. 28, 1994, p. 223.

3. A. E. Waltar and A. B. Reynolds, Fast Breeder Reactors, Pergamon Press, 1981.

4. M. E. Cunningham, C. E. Beyer, P. G. Medvedev, and G. A. Berna, "FRAPTRAN: A Computer Code for Transient Analysis of Oxide Fuel Rods," NUREG/CR-6739, 2001.

5. K. Maeda, K. Katsuyama, T. Asaga, "Fission Gas Release in FBR MOX Fuel Irradiated to High Burnup,” J. Nuclear Materials, Vol. 346 (2005) p. 244.

6. Y. Tsuboi, T. Ogata, M. Kinoshita, H. Saito, "Mechanistic Model of Fission Gas Behavior in Metallic Fuel," J. Nuclear Materials, Vol. 188, 1992, p. 312.

7. C. B. Lee, D. H. Kim, Y. H. Jung, "Fission Gas Release and Swelling Model of Metallic Fast Reactor Fuel,” J. Nuclear Materials, Vol. 288, 2001, p. 29.

8. Y. S. Kim, S. L. Hayes, G. L. Hofman, A.M. Yacout, Modeling of constituent redistribution in U-Pu-Zr metallic fuel, J. Nuclear Materials, v 359, 2006, p 17. 